\title{
MONITORING AND ASSESSMENT OF AIR QUALITY IN THE INTERSECTIONS OF THE TRAFFIC SIGNALS IN TANTA CITY, EGYPT
}

Adel Hewezy $^{1}$, Mobarak Hassany ${ }^{2}$ and Ashraf Zahran ${ }^{2}$

Environmental studies and research institute, El Sadat City University, Egypt

\section{INTRODUCTION:}

The term "air quality" means the state of the air around us. Good air quality refers to clean, clear, unpolluted air. Clean air is essential to maintaining the delicate balance of life on this planet not just for humans, but for wildlife, vegetation, water and soil. Poor air quality is a result of a number of factors, including emissions from various sources, both natural and "human-caused." Poor air quality occurs when pollutants reach high enough concentrations to endanger human health and/or the environment. Our everyday choices, such as driving cars and burning wood, can have a significant impact on air quality.

Manfred Boltze and Wei Jiang (2015) mentioned that traffic signal control is one of the most important instruments to shape urban traffic. They presented the basic outline of an advanced traffic signal control policy which considers the manifold needs of all road users. It calls for a transparent impact assessment and for a holistic view on all impacts of traffic signal control, contributing to overcome the conflicts arising day-to-day in our political bodies in discussions about traffic signal control measures.

Parameters and methods for the impact assessment are proposed. The concept of a situation-responsive prioritization is introduced, paying attention not only to trafficrelated but also to environment-related conditions. Besides comprehensive impact estimation prior to the implementation of traffic signal control measures, the importance of a continuous quality management during operation (i.e. performance measurement) is highlighted. In many aspects such ideal traffic signal control policy may need additional efforts within the responsible institutions. However, the benefits for our society arising from well-designed traffic signal control are very substantial. And innovations and investments in this field must not only address advanced technology and advanced planning instruments but - maybe most important - also an advanced policy.

Traffic signals are a very important instrument to manage urban traffic. When designing traffic signal programs, many different goals and road user needs have to be considered while traffic engineers must ensure the technical planning, implementation 
and operation of traffic signals, their work must be supported by a clear policy. One of the major questions to be answered within such traffic signal control policy is the prioritization of different road user groups at traffic signals.

Traditionally, transit signal priority is one of the most widely implemented priority strategies at traffic signals. There were a large number of studies on various aspects of this priority strategy. An overview of them is available in Nguyen, Van Nam (2013), Garyfalia et al. (2015) and Lin et al. (2015). Another widely implemented prioritization is the preemption for emergency vehicles (EVs), which aim to reduce the delay of EVs at traffic signals and their conflicts with other private vehicles. Some other priority strategies have been proposed in previous research, such as truck signal priority and pedestrian priority (Ramsay and Bunker, 2005; Saunier, N., Sayed, T. and Lim, C., 2009; Seaton, J.J., 2000). Despite of the studies on priority for a single traffic mode, past research has also dealt with prioritization for a multi-modal traffic signal control, which addresses multiple priority requests from several traffic modes (Zamanipour, M., Head, L. and Ding, J., 2014). Recently, also more attention has been paid to consider environmental impacts within traffic signal control (Diegmann, V., 2014; Kohoutek, S., Weinbruch, S. and Boltze, M., 2012). However, there is still a lack of integrated consideration of the trade-offs between different road users and different objectives under various situations within the framework of prioritization.

This study proposed a general policy framework for traffic signal control. While modifications may be necessary to adapt to specific local conditions, it may serve as a blueprint for any urban traffic signal control policy.

\section{LOCATION:}

Tanta is the capital of Gharbia Governorate; a city located at the center of Egypt Delta. It is the country's fifth largest populated area, with an estimated 495,000 inhabitants (2016). Tanta is located between the two largest cities of Egypt (the capital Cairo and Alexandria), it is $94 \mathrm{~km}$. north of Cairo and $130 \mathrm{~km}$. southeast of Alexandria (Fig. 1). 


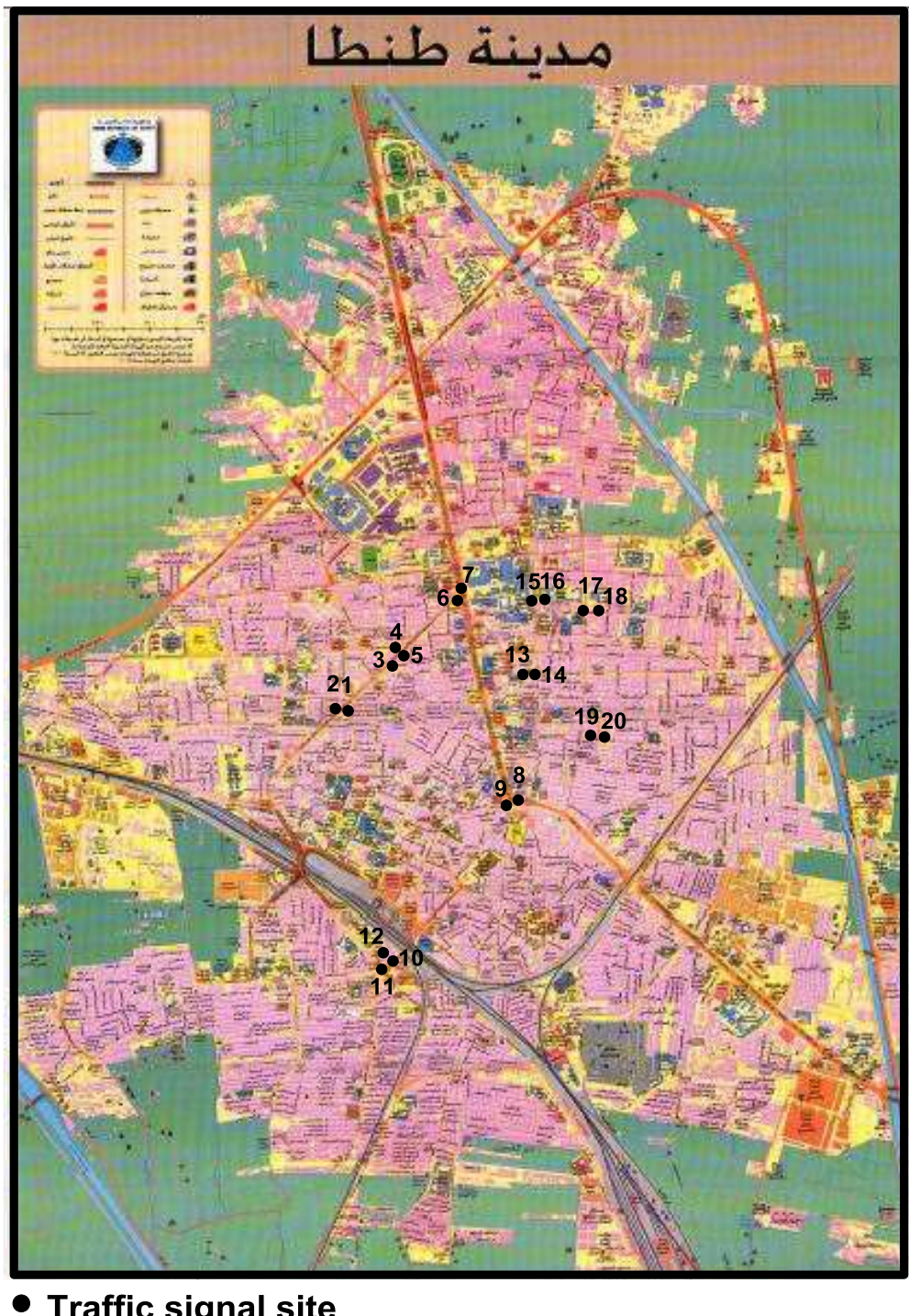

- Traffic signal site

Fig. (1): Location Map of some selected traffic signals in Tanta City, Egypt

\section{MATERIAL AND METHOD:}

To achieve the aim of the study, 20 sites were selected from all over Tanta city representing the intersections of traffic signals in main streets as indicated in figure (1) and table (1). Determination of volatile organic compounds $\mathrm{CO}, \mathrm{SO}_{2}$ and $\mathrm{NO}_{2}$ have been determined by (First Check monitoring instrument) which detect a large range of gases, which are potentially dangerous from both a poisoning perspective. First Check monitoring instrument have many adjustable and selectable features allowing the detector to be used in a variety of ways, which produced by Ion Science Ltd. 
Table (1): Description of the sample locations:

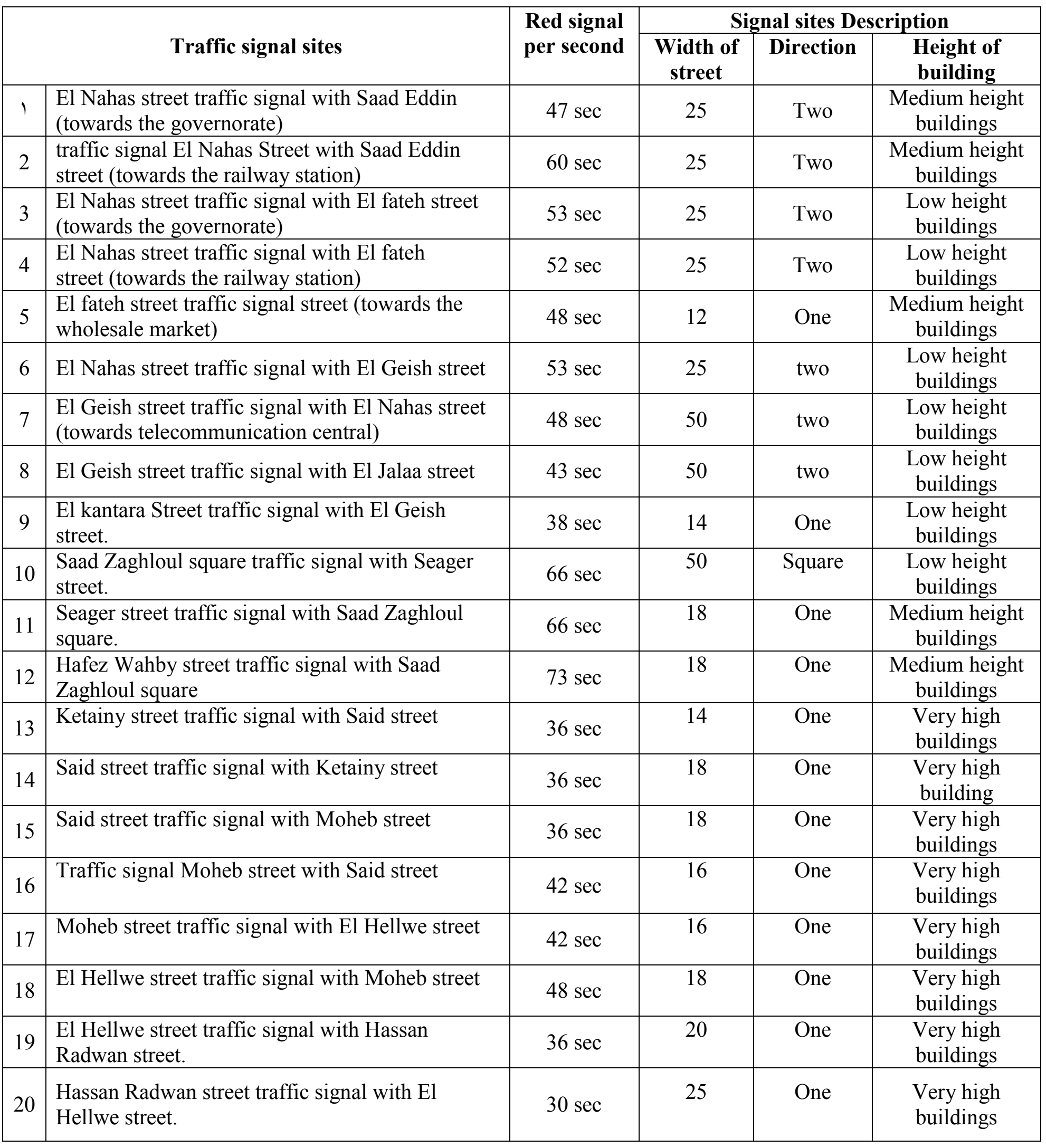




\section{RESULTS AND DISCUSSION:}

The different air pollutants such as $\mathrm{CO}, \mathrm{SO}_{2}$ and $\mathrm{NO}_{2}$ have been measured during the year's season (autumn, winter, spring and summer), (2015 - 2016) at different sites inside Tanta city. These sites represent the signals traffics.

\section{1- DURING AUTUMN:}

It is concluded that the concentration of the three air pollutants $\left(\mathrm{CO}, \mathrm{SO}_{2}\right.$ and $\left.\mathrm{NO}_{2}\right)$ in twelve sites were higher than AQL for $24 \mathrm{hrs}$. measurements $(1,2,3,4,5,6,8,11,12,14,17$ and 18 ). Site number (1) is considerd the hot spot sites of all the studied area since it has recorded high readings of concentrations with relation to the three air pollutants.

While the one-hour measurement of AQL has not been shown on all sites but in one site only ( site no. 5) with relation to $\mathrm{SO}_{2}$ pollutant.

\section{2- DURING WINTER:}

It is concluded that the concentration of the three air pollutants $\left(\mathrm{CO}, \mathrm{SO}_{2}\right.$ and $\left.\mathrm{NO}_{2}\right)$ in fourteen sites were higher than AQL for 24 hrs. measurements ( site no. 1,2,3,4,5,6, $8,9,11,12,13,14,17$ and 18 ). Sites number (1 and 5) are considerd the hot spot sites of all the studied area since they have recorded high readings of concentrations with relation to the three air pollutants.

While the one-hour measurement of AQL has not been shown on all sites but in two sites only ( site no. 5 and 2) with relation to $\mathrm{SO}_{2}$ and $\mathrm{NO}_{2}$ pollutants.

\section{3- DURING SPRING:}

It is concluded that the concentration of the three air pollutants $\left(\mathrm{CO}, \mathrm{SO}_{2}\right.$ and $\mathrm{NO}_{2}$ ) in thirteen sites were higher than AQL for 24 hrs. measurements ( site no. 1,2,3,4,5,6, $8,9,11,12,14,17$ and 18 ). Site number ( 1 ) is considerd the hot spot sites of all the studied area since it has recorded high readings of concentrations with relation to the three air pollutants.

While the one-hour measurement of AQL has not been shown on all sites but in one sites only ( site no. 5) with relation to $\mathrm{SO}_{2}$ pollutant.

The high readings of concentartion of pollutants are well-instrued for the 4- 4- During 


\section{SUMMER:}

It is concluded that the concentration of the two air pollutants $\left(\mathrm{SO}_{2}\right.$ and $\left.\mathrm{NO}_{2}\right)$ in eight sites were higher than AQL for $24 \mathrm{hrs}$. measurements ( site no. 1,2,3,4,5, 8,17 and 18 ). Sites number ( 1,2 and 5) are considerd the hot spot sites of all the studied area since they have recorded high readings of concentrations with relation to the two air pollutants.

While the one-hour measurement of AQL has not been shown on all sites relating to the three air pollutants.

The high readings of concentartion of pollutants are well-instrued for the increasing number of cars, the width of the street and the height of buildings.

\section{RECOMMENDATIONS:}

* Reviewing the situation of the vehicles precisely through the traffic department in order to discover the emissions rates of different vehicles.

* Shortening the time of red traffic signal in order to minimize the emission resulted from the different vehicles.

* Periodic medical examination for traffic policemen at the traffic signals locations as it can be considered a biological detector for the pollution levels.

* Using the smart traffic signals for opening the signals (green signals) and dealing with the traffic crowds at peak time.

* Continuous placing of pollution detectors at high traffic signals to identify the air quality at these signals.

* Committing with the texts of housing and utilities law regarding the heights of buildings as the building height should not exceed (one and a half) the width of the street as the high rise buildings work on the accumulation of the pollutants emitted by the stopped vehicles at red signals as the case of the (first- second) districts in Tanta.

* Tanta city and its affiliated districts (first -second) should work on cultivating some trees that helps in air filtering. 


\section{REFERENCES:}

1- Diegmann, V. (2014): Umweltwirkungen von dynamischen

Verkehrsbeeinflussungsmaßnahmen - eine Übersicht mit Fallbeispielen, Straßenverkehrstechnik (4), pp. 237-245.

2- Kohoutek, S., Weinbruch, S. and Boltze, M. (2012): Reduction Potential of Environment-Responsive Traffic Control on Roadside Particulate Matter and Nitrogen Oxide Concentrations, Transportation Research Record: Journal of the Transportation Research Board, 2270(-1), pp. 162-170. doi: 10.3141/2270-19.

3- Lin, Y., Yang, X., Zou, N. and Franz, M. (2015): Transit signal priority control at signalized intersections: a comprehensive review, Transportation Letters, 7(3), pp. 168-180. doi: 10.1179/1942787514Y.0000000044

4- Nguyen, Van Nam (2013): Bus Prioritization in Motorcycle Dependent Cities. Doctoral Thesis, Technische Universitaet Darmstadt (Germany). tuprints.ulb.tudarmstadt.de/3456/

5- Ramsay, E. and Bunker, J. (2005): Coordinating for priority on urban arterial freight routes, AITPM National Conference, Brisbane, July 28-29.

6- Saunier, N., Sayed, T. and Lim, C. (2009): A Prototype System for Truck Signal Priority (TkSP) using Video Sensors, Annual Conference of the Transportation Association of Canada, Vancouver, British Columbia.

7- Seaton, J.J. (2000): Pedestrian priority planning principles, World Transport Policy \& Practice, 6(2), pp. 32-39.

8- Zamanipour, M., Head, L. and Ding, J. (2014): A Priority System for Multi-Modal Traffic Signal Control, TRB 93th Annual Meeting: Compendium of Papers DVD : January 12-16, 2014, Washington, D.C. National Research Council (U.S.).View publication 